\title{
ESPORTE COMO EXPERIÊNCIA ESTÉTICA E EDUCATIVA: UMA ABORDAGEM FENOMENOLÓGICA
}

\author{
L. M. F. SILVA* e K. O. PORPINO
Universidade Federal do Rio Grande do Norte
silvaleige@yahoo.com.br* \\ Artigo submetido em novembro/2014 e aceito em novembro/2014 \\ DOI: $10.15628 /$ holos.2014.2557
}

\section{RESUMO}

O presente texto constitui-se de um recorte de uma pesquisa de doutorado realizada no programa de pósgraduação em educação da UFRN. Tem como objetivo discutir o esporte a partir da dimensão do vivido, buscando compreender os significados conferidos à prática esportiva e à experiência estética do atleta como educação. Parte de uma abordagem metodológica centrada na fenomenologia como campo de reflexão e interpretação da experiência vivida. Esse entendimento aponta caminhos para uma reflexão sobre o esporte centrada no corpo do atleta, cujos debates teóricos e as intervenções na Educação Física podem transpor qualquer concepção determinista, por uma educação móvel, sensível e inscrita no corpo em movimento.

PALAVRAS-CHAVE: Estética; Esporte; Educação.

\section{SPORT AS BEAUTY EXPERIENCE AND EDUCATION: AN APPROACH PHENOMENOLOGICAL}

\begin{abstract}
This text consists of a cutout of a doctoral research in postgraduate education UFRN program. Aims to discuss the sport from the dimension of lived experience, seeking to understand the meanings conferred to sports practice and aesthetic experience of athlete as education. Part of a methodological approach based on phenomenology as a field of reflection and interpretation of lived
\end{abstract}

experience. This approach franchises also show ways to a reflection on sport centered on the athlete's body, whose theoretical debates and interventions in physical education can overcome any deterministic concept, by a moving education, sensitive and inscribed to the body in movement.

KEYWORDS: Aesthetic; sport; Education. 


\section{INTRODUÇÃO}

No esporte os atletas constituem uma racionalidade não determinada pelos padrões instituídos pela lógica formal, mas uma razão sensível, que se constitui na apreensão dos sentidos e na sua comunicação do corpo com o mundo esportivo.

O esporte gera sentidos que não se restringem à instrumentalização do corpo, ao consumo ou ao mercantilismo. Mesmo quando envolvidos com aspectos relacionados ao rendimento, ao instrumentalismo e ao tecnicismo, os atletas rompem a lógica determinista do esporte criando e recriando formas de existência social e pessoal para além daquilo que foi previsto ou predeterminado.

O corpo do atleta, longe de remeter a qualquer fisiologismo, é de onde irão emergir os sentidos fundamentais dessa experiência, no entrelaçamento dele com o mundo esportivo. Um encontro que permite fruir sentidos, que conduzem a outros modos de existir e que admite a criação de outras linguagens gestuais e novas formas do corpo jogar, educar e se sensibilizar.

Afirmamos que a prática esportiva é uma experiência estética e educativa, em que se opera o sensível pelas sensações reverberadas no corpo do atleta, na dimensão do vivido. Experiência na qual o sensível é apreensão de sentidos e possuidor de significados.

Para traçarmos essa argumentação, utilizamos o filósofo Maurice Merleau-Ponty como referência para pensarmos a dimensão estética do ser atleta, bem como discutirmos os sentidos criados pela experiência vivida no âmbito das práticas esportivas.

Trata-se de uma compreensão fenomenológica da prática esportiva, uma experiência com técnicas e gestos próprios, configurados por uma estrutura rígida. Mas que atravessa os recônditos do corpo, criando em cada atleta um estilo próprio de jogar que educa através do sensível dos movimentos e da gestualidade.

Seguimos com o objetivo de discutir o esporte a partir da dimensão do vivido, buscando compreender os significados conferidos à prática esportiva e à experiência estética do atleta como educação.

Para tal, apoiamo-nos na fenomenologia do filósofo francês Maurice Merleau-Ponty, tendo como referência o mundo vivido do atleta e a experiência da prática esportiva como campo do sensível.

Para transitar nos conceitos da Fenomenologia, enfatizamos como trajeto metodológico neste trabalho a narrativa do mundo vivido e a apreciação estética de filmes.

Iniciamos a reflexão com a narrativa de experiências esportivas. Posteriormente, faremos um diálogo da prática esportiva com as narrativas cinematográficas que tematizam o esporte, a saber: "Olympia" e "Invictus". E em seguida, apresentaremos contribuições da temática para o conhecimento do esporte e para o campo da Educação Física. 


\section{A EXPERIÊNCIA DO JOGAR}

Considerando a experiência estética do corpo no esporte, tendo como referência o mundo vivido e a linguagem corpórea como campo da experiência sensível ${ }^{1}$, faz-se necessário compreender a profusão dos sentidos que os atletas constroem na prática esportiva, revelado pela sensibilidade em quadra, através de alguns elementos como: o tempo-espaço, o olhar, contato com o adversário, a vitória e a derrota e gesto técnico. Então, vamos a eles.

Ocupando um espaço previamente marcado e um tempo delimitado, nós, atletas desencadeamos jogadas e criamos movimentações, que não estão pautadas por uma ordem física e cronológica simplesmente.

Mesmo que a ênfase da movimentação esteja visivelmente coordenada com o tempoespaço do jogo, são eles que se projetam no corpo para conduzirem nossos gestos. E isto expressa, como forma elementar da existência, a indissociabilidade entre tempo e espaço.

Para Merleau-Ponty (2011), o corpo é o espaço, é o tempo, é o movimento, é o lugar. Ainda mais quando ele age e reage no mundo, espaço e tempo não são pontos adjacentes entre si, nem uma relação sintética da consciência. Os movimentos dilatam-se com eles, e entre o que está dado e o vir a ser, o determinado e o indeterminado, o caos e a forma, o corpo pulsa e o gesto simplesmente flui.

Portanto, se toda experiência é corporal, ela é por definição uma experiência espacial. O que permite afirmar que corpo e espaço não são elementos separados, mas se configuram como único ser, enraizados na existência, um corpo no mundo.

É a partir da espacialidade e do tempo que somos no mundo esportivo de modo encarnado. Nossa experiência funda-se em uma perspectiva espaço-temporal e na relação com os elementos da partida, aos quais não temos acesso em sua totalidade, posto ser aberto e inacabado, tratandose de uma relação marcada pelo sentir do corpo em seus movimentos.

Ora, não se trata de um sistema espaço-temporal a priori, sem marcação ou direções distinguíveis, mas um espaço-tempo aberto às condições dos movimentos e das possibilidades que compõem os lugares experienciados pelo nosso corpo, por nós mesmos.

O tempo da partida constrói uma outra temporalidade, medida no corpo. E o esporte aposta nesse corpo que se liberta da demarcação de uma territorialidade fixa, que não se organiza a partir de estratificações numéricas ou justaposições estáticas. Um corpo que muda de gradiente, que perde a localização imposta, que modifica planos, curvas e projeções em função dos movimentos que vai realizando e descobrindo continuamente.

A experiência do jogar, aponta para o delineamento desse corpo e dos acordos que rompem com a estabilidade e com a fixação. Pois seu estado é de criação, conexões autênticas, atualizadas em cada acontecimento da partida e da vida. Afinal, não se pode esquecer que o movimento é inerente à dinâmica do viver. Um modo ativo que o esporte efetua pelos territórios

\footnotetext{
${ }^{1}$ Em suas reflexões Merleau-Ponty (1989) busca compreender o homem a partir da sua experiência vivida, abrindo um imenso leque da relação do homem com seu corpo, com a cultura e com o mundo vivido. $E$, sobre isso ele esclarece que: "A partir do momento em que reconheci que minha experiência, justamente enquanto minha, abre-me para o que não é eu, que sou sensível ao mundo e ao outro, todos os seres que o pensamento objetivo colocado à distância aproximam-se singularmente de mim (MERLEAU-PONTY, 1989, p. 136).
} 
do corpo, engajando entre os sentidos e a inteligência, visão e tato, interioridade e exterioridade, movimentos de afirmação e leitura do corpo no mundo.

Do mesmo modo, o olhar no contexto esportivo enquanto ação presente em todos os momentos da partida, não dispõe somente do nosso potencial enquanto jogadores, mas, junto a isso, do campo visual atado aos movimentos do nosso corpo.

Quando recebemos a bola no ataque, por exemplo, precisamos olhar rápido para saber onde estamos posicionados, a qual distância estamos do gol, onde se encontra o adversário mais próximo e decidir se é possível o passe, o drible, ou mesmo o arremesso ou o gol. Entretanto, quando adquirimos uma certa experiência, o saber latente adquirido pelo corpo lhe dirige à situação requerida de maneira rápida e precisa. Não é mais necessário olhar fixamente para a bola, o posicionamento dos adversários, nem a cor dos uniformes daqueles que nos rodeiam. Depois de alguns anos, basta sentir o jogo, ver com um só olhar tudo e todos ao mesmo tempo.

Assim, o olhar no contexto esportivo não se reduz a uma visão estática. O olho envolve o movimento. Pela movimentação da pupila o visível é alcançado, juntando aquele que vê com o que é visto, uma forma harmônica do corpo com as coisas que se veem. Posto que, não há oposição entre o ver e o visto. Na espessura entre eles acontece a comunicação sem que nenhuma palavra seja soada, fazendo das coisas vistas um elo do visível com o invisível, um diálogo sensível que celebra a existência e instiga o movimento do próprio corpo.

Nessa direção, a visão de quem joga tateia os espaços da quadra se expõem ao olhar do outro e as sensações daquilo que é visto. Uma via dupla que liga um jogador ao outro, a mão à bola, a visão ao movimento, trazendo ao corpo o enigma de ser vidente e visível.

Como afirma Merleau-Ponty (2004b), através do olhar o homem interroga as coisas e compreende o mundo, não por aquilo que está diante de seus olhos, mas pelo seu envolvimento com ele, vivendo-o e inspecionando-o com sua visão. Um entrelaçado que guia o movimento, que anuncia sentidos ao corpo e faz com que ele, com seus sentidos, habite a visão.

Olhar no esporte, antes de ser função é comunicação com esse mundo, é abertura do corpo que assume nessa correspondência determinados comportamentos diante das coisas vistas, afinal, "mover o corpo é visar às coisas através dele, é deixá-lo corresponder à sua solicitação, que se exerce sobre ele sem nenhuma representação" (MERLEAU-PONTY, 2011, p. 193).

Talvez por esse motivo, o jogar seja uma aprendizagem atribuída ao entrelaçamento entre movimento e visão. Um olhar que suscita o movimento, e um movimento que se funde com a visão. Uma via dupla que liga um jogador ao outro, a mão à bola, a visão ao movimento, trazendo ao corpo o enigma de ser vidente e visível, pois "ele se vê vidente, ele se toca tocante, é visível e sensível para si mesmo" (MERLEAU-PONTY, 2004b, p. 17).

Ao interpelar o mundo, o atleta sempre abre novos campos e modos para se exprimir. Uma tarefa sempre inacabada e irrealizável na sua totalidade. Um estado de criação corporal capaz de dimensionar a visão, transformar o invisível em visível, numa dialética de visibilidade construída a partir do olhar corpóreo, do movimento e da subjetividade.

Uma capacidade de ver que permite ao corpo se ligar às coisas e aos outros, instituindo a circularidade dos acontecimentos, nos quais o contato aparece como sintonia de transformação, revelando através desse envolvimento os entremeios da visão e da relação entre o eu e o outro. 
Nessa relação com os outros, sabe-se que na maioria dos esportes, há o contato direto entre os corpos. O envolvimento com os adversários dentro do jogo causa estranheza e provoca os nossos sentidos, não apenas os de repulsa, mas os de empatia e de encantamento. Sensações que se dão entre os gestos que realizamos e as malícias deles para nos deter.

Como afirma Merleau-Ponty (2004a), há no mundo a necessidade do outro, em que ele não é apenas um ser pensante no mundo, nem tão pouco um objeto para mim. Mais do que isso, é o outro eu-mesmo, sem que eu possa dizer que seja eu, pois ele não se reduz a uma formulação minha, mas uma presença comigo, habitantes de um mesmo mundo sensível, um só comigo.

Nesse pensamento, a tensão do encontro com o outro em quadra compõe um conhecimento através da linguagem sensível que se mostra quando nos diluímos-nos um no outro. Porque nosso encontro não se dá por protótipos gestuais, assim como o que criamos para separarmo-nos não são fórmulas ensinadas, mas uma criação sensível que expande o ser, impulsiona para o novo e afeta a existência.

Uma existência atada por um mesmo palco, no qual rompe com a lógica determinista do contato físico e desconstrói o pensamento racionalista da fisiologia mecanicista do estímuloresposta, como algo pronto. Que não nega a rivalidade e a competitividade dentro da quadra, mas que revela o estado sensível do corpo ao ser afetado pela experiência estética dada na relação inacabada com outros corpos, evidenciando que "o movimento da existência em direção ao outro, em direção ao futuro, em direção ao mundo pode recomeçar, assim como o rio que degela" (MERLEAU-PONTY, 2011, p. 228).

Portanto, essa relação intercorpórea com o outro e o vínculo estabelecido nesse contato colocam o corpo como universo aberto para todas as sensações da sensibilidade, numa unicidade de existência que ensina sobre nós mesmos, sobre o outro e expande ontologicamente o viver estético para outra forma de existir.

A intercorporeidade estabelecida nessa relação faz pensar que o homem age simultaneamente por si e pelos outros, criando nesse processo horizontes singulares e de convivência, o que pressupõe que sua existência é pessoal, constituída de um histórico-social como solo de um mundo comum entre os corpos, em que "meu mundo se acha ampliado na proporção histórica coletiva que minha existência privada retoma e assume" (MERLEAU-PONTY, 2011, p. 580).

Assim, o homem vai sendo construído por cenários socioculturais, marcados pelas experiências vividas de desconforto e de paz, de fuga e de empatia, de presença e de ausência. Um circuito mundo-corpo-outro criador de marcas sensoriais inscritas na dinamicidade das relações.

A prática esportiva ensina sobre essa relação, ensina a jogar com o outro na quadra e na vida, ensina a entender o momento de aproximar e distanciar, de ir e de vir, de afagar e de sair, aceitando o outro como extensão significante para se estabelecer criações, provocações e organizações diante da quadra e da vida.

Nessa perspectiva, a alta competitividade nos esportes, se engendra entre outras coisas, pela busca da vitória. Certamente a prática esportiva não se resume a vitória, por isso, vencer ou perder não inclui apenas o placar final.

A díade vitória/derrota representa algo mais para nós que o seu significado imediato. Vitória e derrota constituem uma infinidade de vicissitudes demarcadas sem contexto prévio. Não há limites para as várias formas de envolvimento com o resultado de uma partida ou de uma 
competição. Ele penetra em nossa dimensão corpórea, ampliando a sensibilidade para uma nova forma de sentir e de se entregar ao mundo por intermédio das correntezas da sinergia.

A exemplo de uma derrota, o momento é dado a uma manifestação emocional desencadeada na maioria das vezes pela tristeza, pela raiva e pela frustração, uma espessura de sentidos na textura dos acontecimentos vividos.

A derrota, por exemplo, produz significações mais amplas que a definem como perda. Pois, embora perder faça parte do repertório de todo atleta, na maioria das vezes, ela gera decepção. Como explica Rúbio (2006), diante do resultado obtido e comparando-o com o desejado, é compreensível o sentimento de fracasso do atleta quando ele não consegue atingir sua meta.

Diferentemente da derrota, a vitória traz alívio, alegria e leveza. Ela deixa o corpo leve, tira do chão os pés dos que dela participaram e dos que a comemoram. Seus sentimentos são de euforia, de êxito e de celebração. Traz o afago inebriante, o choro contagiante e retira por algum tempo a sintonia e afinação com a realidade, levando o atleta a uma plenitude una e indivisível que atravessa o corpo e afeta de maneira profunda a sua existência.

No festejo de uma vitória nos misturamos, indistintamente e participamos de um envolvente estado emocional. Sorrimos, gritamos, nos abraçamos, as diversas emoções vão surgindo, envolvendo um corpo ao outro ao mesmo tempo.

Embora a educação ocidental eduque o homem para ser feliz, alegre e vencedor, como se a infelicidade, a tristeza e a perda não fizessem parte da vida, no esporte, os atletas encontram obrigatoriamente o vencer e o perder em seu contexto. Todos pautados por um educar e uma atribuição de um sentido singular, sem a necessária hierarquização da vitória.

Como escreve Lovisolo (2009), uma competição que se expressa em ganhar e perder é a alma do esporte, isto porque, não faz sentido uma em que todos ganhem, inclusive é contra a lógica da competição esportiva. É o risco que o esporte impõe, mas que não deixa de incitar o atleta a viver e se lançar na aventura do esporte, mesmo sem saber o seu resultado. É certo que muitos esportistas entram em competições sabendo que não poderão ganhar, mas desejam estar ali para acumular experiência, para superar desempenhos anteriores, para estarem em uma seleção, para jogarem.

Trata-se de viver o esporte, de ser penetrado por ele e entregar-se ao mundo por intermédio do sensível, da incerteza, do vir a ser. Tendo o corpo como lugar onde as formas de sentir ganhem vida e as coisas do mundo adquiram sentidos, fazendo do esporte um lugar de fundação e afetação humana.

Como ressalta Calvino (1990), para vivenciar a leveza é necessário conhecer a experiência do peso, saber o seu valor. A leveza e o peso de Calvino são perceptíveis dentro do esporte quando o momento vivido conduz à sensação de transformar as limitações do que estar posto, fazendo o corpo buscar novas formas de equilíbrio para oscilar e viver a inconstância esportiva.

As situações antagônicas vividas na prática esportiva ensinam a viver no mundo conflituoso em que vivemos. Não por uma receita determinada, mas uma forma de viver sensível, estabelecida a partir das coisas indeterminadas e imprevisíveis, as quais, permitem expandir os horizontes para novas formas de vida e convivência. 
A prática esportiva amplifica o corpo no mundo, o mundo no corpo. Ela é a forma do corpo em movimento, no qual a alegria e a tristeza revelam, a cada instante, o homem na sua forma de ser, cujas formas podem ser as mais variadas e imprevisíveis. Um viver sensível que faz o corpo, enquanto carne do mundo, abrir-se e entregar-se às manifestações do cotidiano da vida como um estado sempre inacabado de ser com as coisas do mundo.

A experiência sensível inova o corpo, o faz reviver outras significações, uma síntese inacabada sempre ampliada por intermédio da afetação estética. Um mundo aberto aos antagonismos e aos passos de criatividade que se realiza na construção de cada novo movimento do corpo.

Diante disso, dada a imprevisibilidade esportiva, não apenas os resultados que se constroem na variabilidade das situações. As próprias competências para jogar também se constroem nessa situação, quando na dimensão do gesto "correto" ou "incorreto", constitui-se um novo movimento para jogar.

Criamos, a partir da nossa experiência, um mundo de sentidos para cada movimento, para cada gesto. Mas isto supõe um saber independente de qualquer ensinamento, pois o corpo apropria-se do mundo esportivo e dos movimentos ali vivenciados, dando-lhes um significado peculiar para aquilo que foi assimilado.

Como afirma Merleau-Ponty (2011), um movimento é aprendido quando o corpo o compreendeu, quer dizer, quando ele o incorporou ao seu mundo. Tal fato pode ser observado na técnica do arremesso. Quando o corpo aprendeu aquele movimento, não é preciso mais pensar nos detalhes para realizá-lo. O contexto do jogo nos faz realizar. $O$ aprendido não foi um único arremesso, mas a totalidade do movimento no jogo. Corpo, bola e movimento se afinam em significado. O gesto técnico deixa de ser desconhecido, nos misturamos a ele e fundamo-nos corporalmente.

O gesto técnico se abre às interseções do movimento e, no contexto dado, a técnica é reinventada, evidenciando a potência criativa do corpo e a estabilidade instável do gesto técnico. Por isso, o gesto realizado não se reduz a uma mera reprodução, ao contrário, é sempre uma nova implicação do corpo, em sua capacidade de metamorfosear-se, de sentir o jogo e viver o devaneio da criação do gesto esportivo.

Como afirma Merleau-Ponty (2004b), toda técnica é técnica de corpo e ela amplifica a metafísica de nossa carne. Por isso, o esporte não pode ser compreendido em partes, nem em movimentos específicos, haja vista a técnica não está no esporte, nem tampouco em ações ideais, mas na experiência do movimento, na forma como o atleta se dirige ao mundo esportivo e nele se expressa.

A prática esportiva não é reduzida apenas a uma técnica padronizada nem a repetição de movimentos mecanizados, cada ação e conduta realizada estar revestida de sentido que o próprio atleta impõe, fazendo dos gestos uma junção de técnica e sentimento.

Quando corremos, gritamos, vibramos, defendemos ou fazemos qualquer outra coisa em quadra, não utilizamos somente o equipamento anatômico objetivamente. Mesmo que, interiormente haja a ocorrência de reações anatômicas e fisiológicas para cada ato, o corpo não se reduz a um automatismo periférico. O corpo se expressa, vive os sentimentos, vive as sensações, 
em outros termos: "realizar um movimento é realizar os projetos de nossa existência, é saber-se enquanto ser de potencialidades originais" (NÓBREGA, 2005, p. 67).

Assim, mesmo no racionalismo existente no esporte há espaço para o êxtase corporal, que permite que o ser humano, o atleta, e mesmo o espectador explorem o corpo, as sensações, as tensões. Uma entrega de corpo e alma capaz de resultar um novo uso do espaço, um êxtase, uma suspensão no tempo da vida normal, cotidiana.

O esporte transfigura os momentos ordinários da existência, inventa sob novas formas o poder do corpo, um eu posso no tempo, no espaço e na cultura, por meio da motricidade regida pelo próprio corpo.

Isso nos permite dizer que o eu do atleta se apropria de seu viver pessoal e da presença do outro, constituindo um mundo comum de homens finitos, inacabados, corpóreos, historicamente situados e constituídos a partir de uma sensibilidade que se qualifica na intencionalidade dos movimentos guardados no tempo, no espaço e nos rastros da vida. Um trama individual atravessado pelas configurações sociais, que torna evidente a construção da prática esportiva para além dos determinismos e padronizações que lhes são tipificadas, bem como, para além do devir de uma individualização corporal. Afina, os atletas, em meio à dinamicidade esportiva, atribuem sentidos e constroem novas significações por intermédio das sensações do corpo e das construções subjetivas que perpassam o esporte por meio da experiência estética num vínculo do corpo com o mundo.

\section{JOGO COMO DEVANEIO}

Esporte e atleta não são mundos distantes, mas horizontes que existem em unicidade, em que o sensível é a expansão da expressão criativa e perceptiva. E nesse processo, o saber é construído na medida em que experiencia-se o corpo no esporte e vive-se a dor, o sacrifício, o confronto, as regras, mas também a leveza, a graça e o fascínio de ser atleta.

Se o pensamento fenomenológico de Merleau-Ponty reflete sobre a experiência originária de nosso engajamento existencial no mundo por meio do corpo, e considera a existência como fundante da experiência humana e não o pensamento conceitual, entendemos que há no corpo um núcleo de significações em que ele é um contínuo movimento de transcendência ${ }^{2}$ ao mundo.

É nesse cenário que a estética do esporte tenciona valores sensíveis e educativos numa perspectiva que prima pela espetacularização da performance corporal, mas também pelos sentidos e idiossincrasias que ele manifesta nos jogadores e nos seus apreciadores.

Nesse pensamento, acreditamos que os enredos sociais que configuram o esporte apresentam significações estéticas peculiares que extravasam os campos esportivos para difratar-se no conjunto cultural, fazendo-o emergir como prática corporal prazerosa, relativamente dependente e autônoma. E é nesse intuito que buscamos indícios na formação social, para refletirmos sobre o esporte dentro de uma estrutura social mais ampla, configurado dentro de um dispositivo de regulação estrutural e cultural, capaz de afetar o corpo e alargar o

2 O transcendental aqui pauta-se na perspectiva do corpo numa imanência em relação às experiências, ao acontecimento, ao mundo vivido, em que ele passa por uma modulação existencial com a sua realidade circundante (MERLEAU-PONTY, 2004b, 2011). 
horizonte do atleta no mundo, expandindo a existência para uma vida que se constrói a partir dos princípios do educar-se por meio do sensível.

Para isso, utilizaremos duas produções cinematográficas como indicadoras do debate, pelo entendimento de que mesmo que elas recaiam sobre tempos distintos de sua criação, ambas podem formular a representação do imaginário pessoal e social como uma maneira ontológica de existir e de educar-se pelo jogo.

No esporte a ordem e a desordem estão presentes. É na tensão, na incerteza, na imprevisão e na ousadia que as ações dos atletas se desenvolvem. E há, sim, a valorização de condutas para obtenção do sucesso e da vitória. Todavia, é preciso reconhecer que nele não há só ordem imposta, existe também um saber, uma excitação e uma desordem que é gerida por essa dominação.

O ambiente do jogo é essencialmente complexo, aberto, dinâmico e não linear, o que permite ao jogador gerir a ordem e a desordem, numa relação de complementaridade e antagonismos, ou seja, que não estão totalmente entrelaçados, mas são irredutíveis.

Nesse diálogo, há a necessidade de uma constante reorganização das situações decorrentes do jogo. O que imprime ao jogador uma organização desenvolvida entre a ordem, que são regras, regulações e os padrões de movimento do esporte que pratica, e a desordem que integra a modalidade jogada ao jogador como fonte geradora de toda ação ali realizada.

Assim, diante da necessidade de conseguir responder às emergências do jogo, o atleta vive a vertigem como uma maneira sempre nova de jogar. Com ela, a sua existência é colocada em xeque, exigindo novas formas de equilíbrio e de desequilíbrio, de idas e de vindas, de aproximações e de fugas, uma experiência na qual surge uma nova realidade e o atleta transforma as indeterminações em movimentos de vida.

Porpino (2012), ao refletir sobre o corpo, a experiência e a existência por meio do mundo da arte, ou melhor, da experiência vivida a partir dela, convida-nos a reconhecer o corpo como existência, mesmo sabendo que qualquer relato sobre a experiência vivida jamais pode ser confundido com a própria experiência. Pensamos que de modo semelhante ocorre com o atleta no âmbito esportivo. Assim como acontece com o apreciador diante das obras de arte, o atleta em jogo tem a sua existência fundada no vislumbre da sensibilidade que se abre a cada vez que ele se dispõe a jogar. Uma existência capaz de levá-lo à compreensão não apenas daquele contexto, mas dele mesmo, dos outros e do mundo.

Nessa perspectiva, é possível dizer que a prática esportiva causa vertigem, pois ela coloca o atleta a espreita do inesperado, frente aos antagonismos e às instabilidades provocadas na experiência. Afinal, o jogo muda o instante, exige um reordenamento das técnicas e do corpo, incluindo rupturas e fragmentações. Um estado vertigionoso que permite vivê-lo simultaneamente entre a rigidez e a sensibilidade.

Nesse sentido, o caráter organizacional do esporte revela, portanto, uma vertigem desafiadora. Os corpos de formato firme também são sensíveis ao que se passa ao seu redor e em si mesmo, absorvendo o jogo e permitindo um diálogo com as coisas que afetam o mundo da experiência vivida.

Nele, nossa existência é confrontada, e a partir desse momento não somos mais da forma que fomos no último instante. O corpo muda, exigindo novas formas de equilíbrio, de 
desequilíbrio, de correr, de parar, de avançar e de retroceder. Ela nos ensina a reaprender a ver o mundo e a nós mesmos, modificando nossa existência a cada momento.

Tal caminho pode ser percebido nas cenas do filme "invictus". O esporte mostrado, o rúgbi, vai ganhando novos contornos no desenrolar da trama. Vinculado à tenacidade e atrelado a uma ideia de vigor, também dialoga com uma forma de jogar que desconstrói a eficiência moldada pelos ideais olímpicos. Isto porque, a máxima olímpica do "mais alto, mais forte e mais veloz", no filme, é acrescida de valores estéticos como afetação, sensibilidade e significação.

Mais do que jogo previsto é o inesperado que vemos. Ações, ritmos e expressões que ousam o corpo numa dança que liberta e cativa, que silencia e comunica, evidenciando, pelas expressões dos atletas, gestos que eclodem na entrega do corpo aos sentidos efervescentes desse mundo vivido.

Tomando como exemplo, também, a produção "Olympia”, encontramos neste filme uma maneira bastante artística de mostrar o virtuosismo do espetáculo esportivo e a beleza estética dos esportistas em movimento.

Vemos que no ato da competição, as ações, a postura e a própria respiração dos atletas são modificadas, expandindo o corpo para novos horizontes da experiência estética.

A existência do jogo é fundada nesse estado vertiginoso, dos equilíbrios dos desequilíbrios provisórios e contínuos, uma experiência construída na repetição de um novo fazer.

Benjamin (2002), em seus escritos, salientou que o fascínio da criação pela repetição está relacionado ao desejo do novo, do repetir e do saber fazer. Um estado cíclico que refaz o corpo e recria a experiência vivida cada vez que retorna ao seu ponto de partida.

A configuração desse estado vertiginoso representa, pois, condição imprescindível para a construção da prática esportiva, com um teor de sentido social e emocional, que não fica retida em conceitos ou explicações exteriores, mas abarca o homem, incendiando o corpo, e renovando a vida para uma nova existência, bem mais emotiva. Uma estrada esportiva que nos permite encontrar indícios suficientes para dizer que ela se faz na relação tensa entre razão e emoção, dor e prazer, contenção e vazão. Um equilíbrio instável de polos distintos que se conciliam em um princípio de contradição, no qual move o corpo num movimento de contato possível entre eles.

Diante desse sentimento dúbio, retornando ao filme "Invictus", na final da Copa do Mundo de Rugby, 1995, outros momentos são observados, especialmente na mudança de perspectiva das imagens ao acompanhar a sequência de movimentação dos jogadores, suas expressões de controle e descontrole das emoções, bem como a euforia da torcida perante o espetáculo esportivo.

Perante essa tensão, as sensações dos atletas e torcedores variam, baseando-se na tensão formulada pelo próprio jogo. Enquanto os jogadores vivem a tensão entre o não deixar o adversário entrar em seu campo de defesa, ao mesmo tempo essa mesma intenção os move para ataque ao campo adversário. Os torcedores vivem o sentimento dúbio e a apreensão de cada gol, gerando em ambos os casos o deleite e o desprazer, a limitação e o extravasamento como sentimentos cíclicos que o jogo oportuniza.

Assim, atletas e torcedores imersos no jogo de mostrar e esconder, de controlar e expressar, acabam por viver a experiência ambígua e simbiótica ofertada no âmbito esportivo. 
Da mesma forma, em "Olympia", percebemos que os gestos de contenção e evasão tornam-se o elemento que centraliza o ato da transmissão fílmica, guiando a movimentação dos jogos e da nossa atenção.

Os confrontos apresentados e a sensação desencadeada pelas cenas remetem a uma conciliação dialética da aparente oposição entre o autocontrole e o descontrole das emoções. Isto porque, nos dois casos, a busca pela vitória e a tentativa de impedimento da vitória do outro entrarão em sintonia com todos os aspectos da prova e o resultado, independente de qual seja, sempre desembocará numa correnteza de descontentamento/satisfação dos anseios da emoção e do prazer.

Sendo o esporte essa manifestação cultural que lida com sentimentos e emoções, como é o caso do risco, do perigo, do medo, do prazer dentre outros, tem-se nele respostas não planejadas que convidam o atleta a um novo equilíbrio entre a restrição e uma forma de desfrutar emoções que transite sobre esses dois polos de ação.

Assim, considerando todo o contexto competitivo existente no esporte, de uma maneira geral, as características de evasão presentes na maioria das modalidades, a procura da emoção para além de uma representação sentimental, é uma possibilidade de trânsito entre o real e o imaginário, o objetivo e o subjetivo.

Como afirma Elias (1992), no esporte, é possível vislumbrar ao mesmo tempo, de maneira controlada, momentos de autocontrole e descontrole das emoções, um excitamento vivido que transforma-se em prazer.

Essa tensão e relaxamento é o que configuram o excitamento vivido pelas pessoas na prática esportiva, em que o corpo se entrega ao jogo e este desce entre os devaneios da experiência sensível, transformando-se em prazer, afinal, "o desporto é sempre, em todas as suas variedades, uma luta controlada, num quadro imaginário, quer o adversário seja a montanha, o mar, a raposa ou outros seres humanos" (ELIAS, 1992, p. 84).

O esporte não é a única forma de libertar-se das tensões provenientes da vida social, e em particular uma excitação agradável. Mas nele certamente é possível viver o arranjo e o devaneio, características do comportamento social, associando-se inexoravelmente a razão e a emoção, sem separação nem hierarquias, como aspectos que movem os atletas em sua prática.

Para Welsch (2001) é por meio disso que, o esporte se desloca do ético para o estético, quando se torna um espetáculo social, caracterizado pelo "elemento adicional da performance, que revela todos os tipos de habilidades pessoais, a interpretação individual e a abertura para o evento que eles criam (enquanto é criado)" (WELSCH, 2001, p. 153).

A tensão e a excitação, que afetam o atleta diante do jogo, elevam o despertar corpóreo para um universo sensível e redimensionam a vida para uma nova forma de existência que não para de se renovar.

Diante disso, podemos afirmar que a prática esportiva é composta por uma considerável tensão e excitação, dor e prazer, anseio e emoção, elementos cuja ênfase transita entre o ético e o estético, sendo sem dúvida uma prática que permite ao homem sentir e ver o mundo de forma diferente. Pois, mesmo diante dos controles e das determinações, ela é capaz de transportar a existência para uma dimensão corpórea, que revela o homem na sua forma única de existir, e múltipla quanto fruto da experiência de mundo vivido. 
Para ilustrar essa relação de autonomia e dependência, podemos tomar como exemplo novamente o filme "Invictus". A brutalidade e a força, tão características no rúgbi, não se mostram suficientes para um bom resultado. O que nos faz entender que a técnica treinada entrelaça-se à sensibilidade, fazendo os atletas criarem novas escritas para seus corpos em movimento.

Invictus sugere a admiração pela equipe que não tem prestígio nem ascensão no meio esportivo, nos convida a festejar o gol, aponta outras possibilidades de utilização da técnica criativa de jogo, enaltece a diversidade, as ações corporais e a exultação dos corpos que jogam, mostrando que:

O sensível aqui não se apresenta como algo que deva ser eliminado por conter erros, por ser uma ilusão. O sensível define a essência do ser, ele contém significações que singularizam o sujeito e ao mesmo tempo permite a intercomunicação com a singularidade do outro, dando um novo sentido ao acontecimento (NÓBREGA, 2005, p. 70).

Nessa relação de existência corporal, o gesto possui um sentido, uma direção, um significado. Expressão do pensamento desenhado pela gestualidade do corpo, ele caracteriza uma relação sempre original no mundo.

Em "Olympia", percebemos além das roupas, equipamentos e técnicas que, comparados aos de hoje, revelam os investimentos feitos no campo esportivo que tendem a aperfeiçoar as funções orgânicas e gestuais dos atletas. Um aparato tecnocientífico que se manifesta não apenas nos acessórios e roupas, mas também nas instalações esportivas e nos novos materiais, tais como as fibras de carbono, poliéster, elastano, dentre outros, constituintes de vários equipamentos e vestuários esportivos.

Esse movimento de mudanças ocorrido no esporte seja nas roupas, nos usos tecnológicos ou mesmo nas transformações do corpo através das técnicas corporais, por mais que estejam ligados a questões negativas, como consumo e moda, transformam a técnica do jogo e mudam a experiência do atleta a partir de suas próprias idiossincrasias. Isto porque, as novas roupas, assim como os novos gestos, exprimem a capacidade do atleta de transgredir as delimitações das formas de movimento descritas pelos códigos esportivos.

Desse modo, o corpo, ao invés ser subjugado pelos investimentos técnicos e científicos do esporte, se utiliza deles para inscrever novas relações orgânicas e sociais. O que não nega a penetração da razão instrumental e os fins que se procuram, mas desvela o inusitado e o surpreendente, levando o atleta aos campos da existência, condensando suas experiências e fazendo-Ihes florescer enquanto carne do mundo.

Nessa direção, o esporte deixa de ser instrumento de exploração tecnológica, disciplinador e adestrador, reduzido aos aspectos mecanicista e mercantilista. E o corpo, não mais um reprodutor passivo, mas uma condição humana inacabada e itinerante em sua possibilidade de fazer o esporte acontecer.

Embora reconheçamos que corpo do atleta é submetido a um condicionamento físico para adquirir força, resistência, velocidade, muitas vezes, por meio de repetições exaustivas e conhecimento tecnológico para aprimorar sua performance, ele também é preparado para o autodomínio, para superar as condutas dos adversários, para subverter no esporte. 
Como afirma Mauss (2003) há no corpo uma maneira adquirida e não natural de se comportar e se dispor no mundo. E sobre isso, o autor explica que, o corpo enquanto nosso meio técnico de agir no mundo articula gestos específicos e padrões fundamentais, os quais são construídos a partir das particularidades de cada sociedade, revelando ao mesmo tempo, um componente coletivo e individual.

O que nos faz entender que, as conformações estéticas das especificidades dos gestos esportivos são construídas sob esse trama complexo de relações de poderes normativos, técnicos e também estéticos. Na execução controlada e nas características fechadas, o corpo desafia não apenas os regulamentos que Ihes são impostos, mas os seus próprios limites, transcendendo, dentro dos padrões, formas diversas que transformam o repertório gestual do atleta e também do esporte. O que fica claro a partir das múltiplas abordagens do esporte seu leque de significações e compreensões estética e educativa.

\section{ESPORTE: O JOGO COMO EDUCAÇÃO}

Todo esporte existe dentro de um mundo previamente delimitado, dedicado à vivência de uma atividade pré-configurada por regras e procedimentos técnicos e táticos, entretanto, ele necessita de particularidades para que possa acontecer. No campo do vivido, suspenso da realidade corrente, ele se legitima, abre o homem ao mundo, revestindo de significado a vida daqueles que o praticam. Por isso, ele passa a ter função a serviço dos valores e do sentido do humano, características propensas à compreensão do esporte como uma expressão da razão do excesso, da transcendência e da excentricidade, isto é, da razão da liberdade.

Acreditamos que no esporte, mesmo diante do rigor e das duras exigências, a experiência sensível do atleta não se deixa anular pela disciplinarização e funcionalidade do esporte, de ascese $^{3}$, por exemplo.

Afirmamos que o esporte pode revelar-se como experiência estética e educativa, tendo em vista a possibilidade de viver o corpo para além dos muitos preconceitos e limites impostos pelos códigos sociais. Nele há um arrebatamento tamanho, uma imbricação tão forte, e uma entrega total àquele momento, que somente quem foi ou é atleta reconhece, a partir da experiência vivida, a forma como o jogo é sentido no corpo.

Nesse pensamento, a experiência esportiva reabilita o sensível, transcende a própria materialidade do esporte e transfigura a vida, pelo viver estético do atleta na ação do jogo.

O estado de jogo permitido pelo esporte, ou seja, a disposição estética do atleta diante daquela experiência possibilita à razão se iniciar no campo da sensibilidade e a rigidez de sua estruturação passar a ser despedaçado dentro da dimensão sensível ali encontrada. Isto porque, o atleta é envolvido de tal maneira que o esporte é uma oportunidade para instalar no corpo a razão, a animalidade, a ética e a estética de sua condição humana.

\footnotetext{
${ }^{3} \mathrm{O}$ esporte em sua relação com o atleta visto pelo viés ascético diz respeito à produção de modos de ser e de relacionar-se consigo e com os outros, por meio de uma prática que exige esforço, repetição e renúncia.
} 
O jogo é fundamental, já dizia Schiller $(1995)^{4}$. A experiência do jogar permite ao homem uma passagem da sensação ao pensamento e do pensamento à sensação, como totalidade ontológica da existência, imbricada com as coisas do nosso fazer, do pensar, do sentir e do movimentar.

Na teoria estética de Schiller (1995) o jogo tem um sentido educativo, ele aparece como elemento da cultura humana, ligando dois aspectos fundamentais do homem, a razão e a sensibilidade.

É através do jogo, na satisfação do impulso lúdico que Schiller (1995) reconhece a integralidade do homem. Tal impulso, o lúdico, não é um instinto particular ou espontâneo, mas uma imanência entre o biológico e o sensível, entre a razão e a emoção. É o equilíbrio que possibilita encontrar as limitações da sensibilidade e da razão a atuar juntas, sem que uma sobreponha à outra.

Nessa condição necessária para um ideal de educação, o corpo em movimento, o homem que joga pode evidenciar os fundamentos para a grandeza e excelência da humanidade, de tal maneira que "o homem joga somente quando é homem no pleno sentido da palavra, e somente é homem pleno quando joga" (SCHILLER, 1995, p. 84).

Assim, o jogo revela-se como princípio de beleza da humanidade, de interação entre os sentidos e a razão, e também de liberdade do sentir, sendo capaz de superar essas oposições.

Com isso, surge o prazer estético, o jogar como experiência significativa que torna o jogo uma possibilidade de educação, tendo no estado lúdico a possibilidade do homem tornar-se integralmente homem, não por meio didático, mas como experiência que faz o sujeito conhecedor do mundo.

Reconhecemos que as relações entre o lúdico, o estético e o educativo não se referem a qualquer prática esportiva, mas a um esporte que envolve o atleta pela dimensão estética do existir, em suas ambivalências e imponderações. Nas indeterminações, nos diálogos e nas criações do viver estético que rompem as barreiras do determinismo das coisas prontas, ecoando nos recônditos do corpo, uma variedade de sentidos e significados.

O mesmo leque que faz do esporte uma prática disciplinar e rígida, dimensiona o atleta para uma experiência ontológica e saber estético imbricados com as coisas do sensível e do fazer humano.

Sendo o atleta corpo, corpo próprio, ele opera sua percepção, seu movimento e sua reflexão, não como dados isolados da ordem do eu penso ou da funcionalidade momentânea, mas da ordem do poder, do fazer e do sentir. Todos pautados nas relações estabelecidas nessa experiência e no potencial do corpo em significar e criar sentidos na existência.

Conforme Merleau-Ponty (2011), o corpo é o elemento fundamental na construção do saber humano, em que o conhecimento não ocorre por meio de um corpo dotado de aptidões

\footnotetext{
4 Não se trata aqui de uma semelhança conceitual entre jogo e esporte, mas sim algumas relações que fazem com que, se o primeiro pode se transformar no segundo, o esporte também pode vir a ser um jogo, sobretudo, por meio da dimensão sensível, no fazer estético do corpo. Nessa relação, compreendemos que o esporte é apenas uma das manifestações de jogo, dentro de um contexto bastante socializado e universal.
} 
físicas e intelectuais inatas, mas nas relações empregadas no mundo e nos sentidos nele encontrados.

Saberes que nascem e se fazem no corpo e nas relações experienciadas no mundo, sendo ao mesmo tempo percepção e reflexão, intelectualização e sensibilização, pautados na razão dos meios sensíveis e na emoção dos meios inteligíveis, derivados das experiências pelas quais o corpo vive no mundo e pela percepção que temos dele.

Sendo assim, pode-se pensar o esporte como uma experiência educativa, uma compreensão da prática esportiva como possibilidade de compreender o ser humano na sua totalidade, naquilo que emerge do corpo. E isso acontece quando o jogo é jogado, ou seja, quando considera-se a prática esportiva a partir dos sentidos e sensações do jogador, na entrega ao desejo de jogar.

Isso é essencial para a educação e, em particular, para a Educação Física, por dar voz ao corpo, ao mundo vivido dos alunos e dos atletas como condição de existência, que se configura na relação consigo, com os outros e com o mundo.

Compreendemos que o esporte, em sua versatilidade e multiplicidade, é capaz de abrir espaços para diversos corpos, diversos movimentos e suas mais variadas experiências estéticas, permitindo que o homem habite no tempo e no espaço do humano e não da máquina, criando sempre novos sentidos para si e para a sociedade.

Afinal, o esporte é um universo de significações estéticas e educativas. Guarda sim fios lógicos, rígidos e concretos, de razão e de estruturação, mas tece igualmente a tudo isso um educar que fomenta a liberdade de criar, de sentir, de recomeçar, de reinventar, e entre as múltiplas possibilidades do movimento humano, permite viver o tempo, o espaço, o mundo e os outros como uma fenomenologia do corpo e do movimento.

\section{CONSIDERAÇÕES FINAIS}

Reafirmamos o que foi dito no início desta escrita: a prática esportiva é uma experiência estética e educativa, a partir das sensações reverberadas no corpo, no diálogo sensível do atleta neste mundo.

A experiência estética da prática esportiva e as análises das obras cinematográficas são exemplos dessa relação, em que, nas ações do jogo o atleta ultrapassa as fronteiras biológicas e normativas do esporte, cria e recria movimentos, vivencia situações de afetos e de confrontos, de emoções e de paixões, atribuindo sempre novos sentidos por meio da estesia que o esporte revela ao atleta.

Nas dinâmicas relações que apresentamos do atleta em jogo, evidenciamos que o esporte se revela como jogo, como força viva da existência, sendo o sensível e o lúdico a condição essencial e fonte incitativa para o corpo que joga. Pois ele acontece nas oscilações do viver, vinculando-se aos sentimentos e às sensibilidades de forma fecunda e motivadora, fazendo-se, simultaneamente, lúdico, estético e educativo.

Compreendemos o esporte como prática estética e educativa, pois, mesmo sendo conduzido por uma ótica de natureza universal, possibilita uma vivência autônoma que se dá pelo 
processo paradoxal do jogo, na abundância do corpo, configurando-se como contemplação permanente do devir, do transcender e do existir.

Propondo novos anúncios para o esporte, é fundamental repensá-lo a partir dos princípios lúdicos aqui revelados. Ao invés de olhá-lo pela ótica opressora, é preciso enfatizar a experiência e as sensações daquele que joga, que comporta o surpreendente, o indivizível, que rompe a mecanização gestual, não se fixando em regras preestabelcidas, que busca o prazer de simplesmente jogar com a bola, com os outros e com o mundo que o cerca.

Vale salientar que não negamos a busca pelo resultado, nem propomos o esquecimento das técnicas padronizadas do esporte. Mas as valorizamos como processos dinâmicos e criativos, que ultrapassam os limites impostos pelas codificações, reinventando-se e reconstruindo simultaneamente o atleta, o esporte e o mundo.

Esse entendimento aponta caminhos para a Educação Física, que, tendo como um dos conteúdos o esporte, pode possibilitá-lo como jogo e incorporar a capacidade do repetir, do refazer e do brincar, recusando os princípios rígidos que possam impedir as mudanças, o jogo como devaneio e as ousadias do movimento.

Os jogadores, sujeitos das ações pedagógicas realizadas, devem compartilhar entre si a alegria de vivenciar o processo e se apropriar do produto de suas ações. E isso não nega o esporte de rendimento, nem os modelos gestuais, mas permite que na experiência esportiva todos tenham chance de brincar com tais elementos, de criticá-los e de ousar transformá-los com as ações desenvolvidas, com o corpo dos colegas e com o próprio corpo.

Acreditamos que a Educação Física pode possibilitar o esporte como jogo e incorporar a capacidade do repetir, do refazer e do brincar, recusando os princípios rígidos que possam impedir as mudanças, o jogo como devaneio e as ousadias do movimento.

Conforme ficou evidenciado ao longo deste estudo, buscamos o alcance de uma reflexão do esporte centrada no corpo como abertura ampla dos sentidos para as coisas do sensível, nas quais o viver estético transpõe qualquer concepção determinista, que se resume ao mundo da mercantilização, disciplinarização e mecanicismo.

O corpo que joga, que brinca com o tempo e com o espaço, que vivencia o contexto complexo do jogo, suas vertigens, tensões, excitações e paradoxos, educa-se pelo sentir, pelo fazer e pelo repetir. Vemos que o mundo esportivo não se esgota em propostas e possibilidades, pelo contrário, é um lugar imprevisível e inconstante que permite ao corpo rasgar o tempo, lançar-se no espaço, jogar com as regras e ser homem no pleno sentido da palavra.

Temos certeza de que este trabalho não finda por aqui, uma vez que qualquer pesquisa ou leitura que fazemos de um fenômeno é sempre parcial e inacabada. Portanto, estamos longe de produzir verdade, certeza e acabamentos diante do conhecimento sobre o esporte.

A partir disso, reafirmamos a contínua tarefa e o desafio da Educação Física diante da temática exposta. Não que sejamos os únicos nesse trabalho, mas que possamos propagar o esporte para além do aspecto da instrumentalidade, e quem sabe, continuar alcançando sentidos sensíveis para o corpo e para o movimento humano. 


\section{REFERÊNCIAS BIBLIOGRÁFICAS}

1. BENJAMIN, Walter. Reflexões sobre a criança, o brinquedo e a educação. Tradução de Marcus Vinicius Mazzari. São Paulo: Duas cidades, 2002.

2. CALVINO, Ítalo. Seis propostas para o próximo milênio: lições americanas. Tradução de Ivo Barroso. São Paulo: Companhia das Letras, 1990.

3. ELIAS, Nobert; DUNNING, Eric. A busca da excitação, Lisboa: Difel,1992.

4. LOVISOLO, Hugo. Competição, cooperação e regulações. In: LOVISOLO, Hugo; STIGGER, Marco. Esporte de rendimento e esporte na escola. Campinas, SP: Autores Associados, 2009, p. 211-217.

5. MAUSS, Marcel. Sociologia e antropologia. Tradução de Paulo Neves. São Paulo: Edusp, 2003.

6. MERLEAU-PONTY, Maurice. Os pensadores. São Paulo: Nova Cultural, 1989.

7. ___ Conversas. Tradução de Fabio Landa; Eva Landa. São Paulo: Martins Fontes, 2004a.

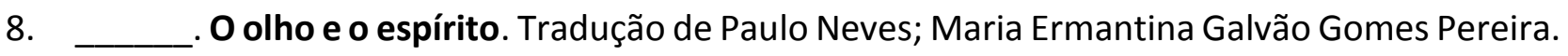
São Paulo: Cosac \& Naify, 2004b.

9. ㄴ. Fenomenologia da percepção. Tradução de Carlos Alberto Ribeiro de. Moura. São Paulo: Martins Fontes, 2011.

10. NOBREGA, Terezinha Petrucia da. Corporeidade e educação física: do corpo objeto ao corpo sujeito. 2. ed. Natal: EDUFRN, 2005.

11. PORPINO, Karenine de Oliveira. experiência e conhecimento, 3., 2012, Natal. Anais eletrônicos... Natal: UFRN, 2012. Disponível em: <http://coloquiodocorpo.com.br/>. Acesso em: 5 set. 2012 .

12. RUBIO, Kátia. O imaginário da derrota no esporte contemporâneo. Psicologia \& Sociedade, Porto Alegre, v. 18, n. 1, jan./abr. 2006.

13. SCHILLER, Friedrich. A educação estética do homem. Tradução de Roberto Schwarz e Márcio Suzuki. São Paulo: Iluminuras, 1995.

14. WELSCH, Wolgang. Esporte - Visto esteticamente e mesmo como arte? In: ROSENFILD, D. L. (Org.). Ética e estética. Rio de Janeiro: Jorge Zahar, 2001. 